or kneeling, ought to be tried, which, by an additional force, may help to push along the head and alter its direction when it does not advance in the right way. Nevertheless, the patient must by no means be too much fatigued."

Could it be better said? To-day if the patient is "too much fatigued" forceps application, preferably under local anaesthesia, is so safe in skilled hands as to make much of the discussion about position in the second stage of labour unprofitable.

\section{Acne: Tetracycline or Not?}

Most people in Great Britain, whether medical or lay, will have tried their hand at treating acne vulgaris at one time or another. It lends itself to private enterprise. Sufferers abound, the lesions are conveniently situated so that their progress can be followed without the need for undressing or for the use of special instruments, and the natural variability of the condition ensures continuing interest week by week as the latest remedy is assessed.

The decision on which to apply of most of the treatments available can hardly be considered vital. The choice between one sulphur lotion and another, for instance, will make little if any difference to the outcome. But in the last few years systemic antibiotics have been advocated for the treatment of acne, and in the consideration of these flippancy must depart. Tetracycline and its relations have been the chief drugs suggested, dosage usually starting at $250 \mathrm{mg}$. four times a day and falling gradually, against the usual canons of antibiotic therapy, even down to $100 \mathrm{mg}$. daily in some reports. The recommended course usually lasts some months.

Apart from the expense entailed, these drugs have undesirable side-effects of varying incidence and severity which must be weighed against their therapeutic effect. The most important are nausea and vomiting, presumably due to a direct action on the gastric mucosa, and superinfection by antibiotic-resistant organisms. Among these are Candida albicans, Proteus and Pseudomonas species, and Staphylococcus aureus. ${ }^{1}$ Liver toxicity has also been reported, notably in asseciation with pregnancy and with high dosage. ${ }^{2}$ Photosensitization may occur, especially in patients exposed to strong sunlight, while inhibition of protein synthesis has been postulated as the cause of the hypoplasia of tooth enamel and retardation of bone growth occasionally seen. ${ }^{3}$ Tetracyclines are also deposited in bones and teeth which are calcifying, causing a permanent discolouration. Consequently clear-cut evidence that these antibiotics in fact help to clear the lesions of acne or prevent new ones from developing would be welcome. This is where the difficulty lies.

The natural variability of acne is so great that any assessment of therapy is difficult. What is more, anyone with much experience of treating acne will have been

\footnotetext{
1 Barber, M., and Garrod, L. P., Antibiotics and Chemotherapy, 1963. Edinburgh and London.
Brit. med. $7 .$, 1964, 2, 1545

2 Brit. med. 7., 1964, 2, 1545.

- Wansker, B. A., ibid., 1961, 84, 96.

5 Hicks, J. H., Sth. med. F. (Bgham, Ala.), 1962, 55, 357

Stewart, W. D., Maddin, S., Nelson, A. J., and Danto, J. L., Canad. med. Ass. F., 1963, 89, 1096.

Cronk, G. A., Naumann, D. E., Heitzman, E. J., Marty, F. N., McDermott, K. J., and Vercillo, A. A., Arch. Derm., 1956, 73, 228. Stritzler, C., and Frank, L., ibid., 1960, 81, 958.

- Cornbleet, T., ibid., 1964, 89, 144.

10 Smith, M. A., Waterworth, P. M., and Curwen, M. P., Brit. F. Derm., $1962,74,86$.

1 Crounse, R. G., 7. Amer. med. Ass., 1965, 193, 906.
}

impressed by the frequency with which patients report an initial improvement on almost any remedy. In other words, the expectancy of the patient often brightens his own assessment of the severity of his acne and, perhaps less often, even produces actual improvement of the lesions. There are many reports of the favourable effects of systemic antibiotics in trials both with ${ }^{4-6}$ and without ${ }^{7-9}$ a placebo, but in two double-blind cross-over trials with a placebo ${ }^{1011}$ there was no significant difference between these drugs and the placebos. What therefore is one to do until the situation is further clarified ?

In the first place tetracycline and related drugs should probably seldom, if ever, be given for acne to pregnant women or to children when the teeth are still calcifying. People with hepatic or renal impairment should be especially carefully watched. The milder cases of acne would not seem to call for this treatment. There is no good evidence yet that antibiotics are particularly effective in clearing up certain types of acne, such as the predominantly cystic or pustular varieties, although it is a widespread clinical impression that they are. The difficult cases, in which the usual homely remedies have been tried and found wanting, are the ones where the temptation to prescribe antibiotics becomes acute. Should it be resisted ? Opinion at present seems to be divided.

\section{New Year Honours}

Baroness Summerskill has beeī created a Companion of Honour in this year's New Year Honours, for her political and public services. After serving on the Middlesex County Council from 1934 to 1938 she was returned to Parliament in that year and sat in the Commons continuously until 1961, when she was translated to the House of Lords. Ever a champion of social justice and welfare, she was Minister of National Insurance from 1950 to 1951 and chairman of the Labour Party from 1954 to 1955.

Surgeon Vice-Admiral Sir Derek Steele-Perkins receives the K.C.B. for his outstanding services as Medical DirectorGeneral of the Royal Navy since 1963. Graduating from Edinburgh in 1930, he entered the Navy two years later, and accompanied the Queen on her visits to the Commonwealth in 1953-4 and 1959. The knighthood conferred on Dr. Ludwig Guttmann is a further recognition of his services at the National Spinal Injuries Centre at Stoke Mandeville to patients disabled by paraplegia. A former director of the department of neurology and neurosurgery at the Jewish Hospital in Breslau (now Wroclaw), Dr. Guttmann came to Britain as a refugee in 1939, and after working in the department of surgery at Oxford became director of the Centre in 1944. Professor I. W. J. McAdam's far-sighted direction of the department of surgery at Makerere University College Medical School at Kampala, Uganda, has been recognized by the conferment of a knighthood. It comes at a time when medical men from Britain are playing an important part in helping emergent nations in Africa and elsewhere to develop their medical schools. Professor A. A. Miles, who also receives a knighthood, has made many distinguished contributions to bacteriology. $\mathrm{He}$ is director of the Lister Institute of Preventive Medicine and has been Biological Secretary of the Royal Society since 1963. Before going to the Lister Institute he was director of the M.R.C. Wound Infection 